\title{
The World Journal of Surgery Welcomes Dr. Ross Roberts to the Editorial Board
}

\author{
Julie Ann Sosa ${ }^{1}$
}

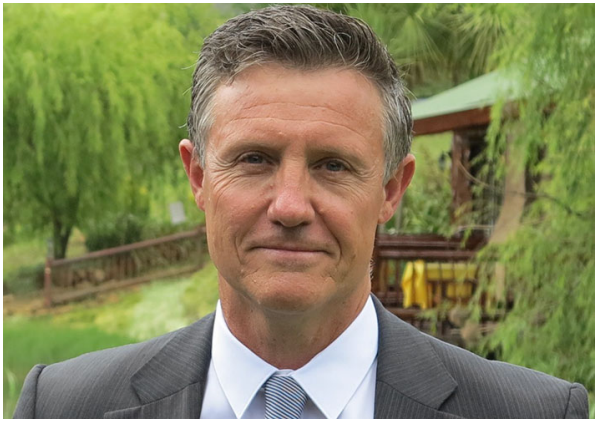

Dr. Ross Roberts was born in the coastal town of Knysna in South Africa and then attended medical school at the University of Cape Town before moving to New
Zealand as a young doctor. Surgical training was undertaken in New Zealand followed by post fellowship training in upper gastrointestinal surgery at Groote Schuur Hospital, Cape Town. He currently works at Christchurch Hospital in New Zealand with a specialist and research interest in esophagogastric malignancy, gastroesophageal reflux and motility disorders plus abdominal hernia surgery. Dr. Roberts has served at the President of the Australia and New Zealand Gastric and Oesophageal Surgery Association and remains actively engaged in educational activities to promote progress in this area. His lifelong passion has been the pursuit of trout in beautiful places such as in New Zealand.

Publisher's Note Springer Nature remains neutral with regard to jurisdictional claims in published maps and institutional affiliations.
Julie Ann Sosa, MD, MA, FACS—Editor in Chief, World Journal of Surgery.

Julie Ann Sosa

julie.sosa@ucsf.edu

1 University of California at San Francisco-UCSF, San Francisco, USA 